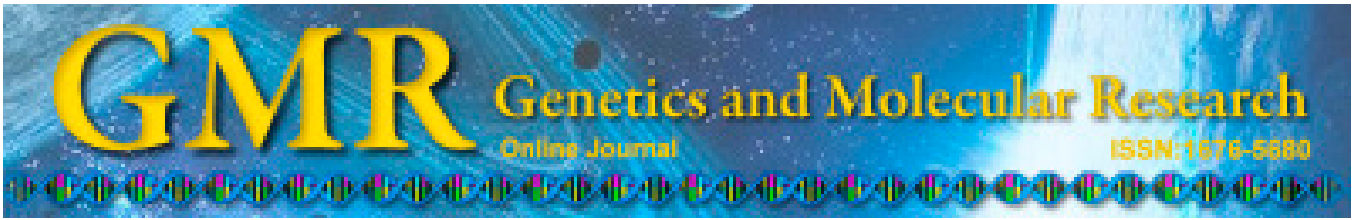

\title{
Reaction norms for the study of genotype- environment interaction for growth and indicator traits of sexual precocity in Nellore cattle
}

\author{
M.V.A. Lemos, H.L.J. Chiaia, M.P. Berton, F.L.B. Feitosa, C. Aboujaoude, \\ G.C. Venturini, H.N. Oliveira, L.G. Albuquerque and F. Baldi \\ Departamento de Zootecnia, Faculdade de Ciências Agrárias e Veterinárias, \\ Universidade Estadual Paulista, Jaboticabal, SP, Brasil \\ Corresponding author: F. Baldi \\ E-mail: fernandobaldiuy@gmail.com
}

Genet. Mol. Res. 14 (2): 7151-7162 (2015)

Received August 8, 2014

Accepted February 5, 2015

Published June 29. 2015

DOI http://dx.doi.org/10.4238/2015.June.29.9

ABSTRACT. The objective of this study was to quantify the magnitude
of genotype-environment interaction (GxE) effects on age at first
calving (AFC), scrotal circumference (SC), and yearling weight (YW)
in Nellore cattle using reaction norms. For the study, 89,152 weight
records of female and male Nellore animals obtained at yearling age were
used. Genetic parameters were estimated with a single-trait random-
regression model using Legendre polynomials as base functions. The
heritability estimates were of low to medium magnitude for AFC ( 0.05
to 0.47 ) and of medium to high magnitude for SC $(0.32$ to 0.51$)$ and
YW ( 0.13 to 0.72 ), and increased as the environmental gradient became
more favorable. The genetic correlation estimates ranged from 0.25 to
1.0 for AFC, from 0.71 to 1.0 for SC, and from 0.42 to 1.0 for YW. High
Spearman correlation coefficients were obtained for the three traits,
ranging from 0.97 to 0.99 . The reaction norms along the environmental
gradient of 10 sires each with the highest or lowest breeding value 
for YW predicted by single-trait analysis demonstrated more plastic phenotypes for YW and more robust phenotypes for SC. The effect of GxE was most important for $\mathrm{YW}$ and $\mathrm{AFC}$ with respect to SC. When animals are selected for higher SC or YW or lower AFC, considering or not the GxE effect, it is expected that the same animals will be selected. The reaction norms obtained based on sire breeding values along the environmental gradient showed that animals with extreme breeding values respond differently as environmental conditions improve.

Key words: Beef cattle; Legendre polynomials; Scrotal circumference; Yearling weight

\section{INTRODUCTION}

A reduction in age at first calving (AFC) is directly related to the efficiency and profitability of beef production. Furthermore, the availability of animals for sale and for selection is known to be greater in herds with a larger number of sexually precocious animals, which permits higher selection intensities and consequently increasing genetic progress. Several aspects need to be improved in Zebu breeds, with the most important being the low sexual precocity of these animals. In this respect, studies have shown that scrotal circumference (SC) is negatively and therefore favorably correlated with $\mathrm{AFC}$, with the genetic correlation ranging from -0.13 to -0.44 (Pereira et al., 2002; Dias et al., 2003; Boligon et al., 2007).

The selection of animals for higher weight at young ages is a common practice in beef cattle breeding programs. As a consequence, weight records are important in genetic breeding programs and are used as selection criteria in conjunction with SC. Yearling weight (YW), which is the last weight record obtained by most breeders of selection herds before the sale of bulls, is the weight closest to slaughter weight and therefore shows the highest correlations with the latter.

The effect of genotype-environment interaction (GxE) occurs when two or more genotypes show different performances in different environments (Komoldin et al., 2002). This interaction is expressed in different manners and at different intensities, with the most extreme being represented by the inversion of genotype classification depending on the environment where the animals are evaluated (Falconer and Mackay, 1996). Consequently, the performance of animals and their offspring can change according to the environmental conditions in which each of them was selected. GxE can cause changes in genetic, phenotypic and environmental variances, which in turn, may alter selection criteria depending on the environment (Alencar et al., 2005).

Some studies have used reaction norm models to evaluate the presence of GxE effects (Corrêa et al., 2009; Pégolo et al., 2009). These norms describe the expression of a genotype as a linear function (reaction norm) of an environmental value or gradient. This analysis uses covariance functions that are obtained with random-regression models, in which an environmental value is usually defined as the mean performance of all genotypes in that environment (Kirkpatrick et al., 1990). In beef cattle, few studies have investigated the effect of GxE on indicator traits of sexual precocity (e.g., AFC and SC) in Zebu breeds and on growth traits such as YW using reaction norms under tropical conditions. Therefore, the objective of the present study was to evaluate the magnitude of GxE effects on growth and reproductive traits in Nellore cattle using reaction norms. 


\section{MATERIAL AND METHODS}

\section{Description of the data}

The initial database contained 89,152 YW records of female and male Nellore animals, 41,836 records of SC at yearling, and 28,871 records of AFC. The data were collected from 1984 to 2007 in 29 herds participating in the Conexão Delta G Breeding Program of Nellore cattle. The animals were raised in the north (Tocantins State), northeast (Bahia State), midwest (Mato Grosso, Mato Grosso do Sul and Goiás States), and southeast (São Paulo State) regions of Brazil. The main objective of the farms participating in the program is the sale of young bulls and animals for slaughter. Bulls and cows were kept on pasture with ad libitum access to mineral salt. The breeding season of cows began in November and lasted approximately 70 to 90 days. Some farms performed an anticipated breeding season for heifers aged 14 to 16 years from January to March, which lasted approximately 60 days. All heifers were exposed to bulls irrespective of weight and body condition. The mean age of the animals at measurement of YW and SC was $517 \pm 47$ days.

\section{Environmental gradient}

The environmental gradients (EGs) were defined as a function of animals born in the same herd and year, from the same management group (from birth to yearling), and of the same sex, for $\mathrm{AFC}, \mathrm{SC}$ and $\mathrm{YW}$, respectively. The post-weaning weight gain was used as a criterion to evaluate the EG (average performance of all animals in each environment). This criterion was chosen because the herds differ most in environmental conditions in the post-weaning period. The dry season for some farms in this period lasts up to 6 months. The average post-weaning weight gain was estimated for each EG and standardized to a mean of 0 and variance of 1 . EGs with a standardized post-weaning weight gain above +2.5 standard deviation units were defined as EG $=+2.5$ (upper limit) and those with a standardized post-weaning weight gain below -2.5 standard deviation units were defined as EG $=-2.5$ (lower limit). The standardized EGs were subjected to an iterative process as described by Calus et al. (2004) to correct bias in the estimates of EGs caused by the non-random use of sires or by the small number of animals in some herds.

\section{Estimation of genetic parameters}

In the analysis of reaction norms for YW, AFC and SC, linear Legendre polynomials regressed on the EGs were used to model additive genetic effects. Linear Legendre polynomials were also used to model the fixed effect of the average population trend.

The contemporary groups were defined using data of farm, year and management group (at birth, weaning and yearling) for the three traits. The effect of sex was only considered for YW. The random-direct additive genetic effect and the fixed effects of contemporary group were included in the model. For the three traits, observations outside the interval given by the mean of the contemporary group ( \pm 3.5 standard deviations) were excluded. Contemporary groups with less than 10 observations were also eliminated. The residual variances were modeled as homogenous classes. The matrix representation of the complete model was:

$$
\boldsymbol{y}=\boldsymbol{X \beta}+\boldsymbol{Z a}+\boldsymbol{e}
$$

Genetics and Molecular Research 14 (2): 7151-7162 (2015)
(Equation 1) 
where $y$ is the vector of observations (AFC, SC or YW), $\beta$ and $\alpha$ are vectors of the fixed effects of direct additive genetic and residual coefficients, respectively, and $X$ and $Z$ are the incidence matrices of $\beta$ and $\alpha$, respectively. According to the model, the following assumptions were adopted:

$$
E\left[\begin{array}{l}
y \\
a \\
e
\end{array}\right]=\left[\begin{array}{c}
X b \\
0 \\
0
\end{array}\right] ; \quad V\left[\begin{array}{l}
a \\
e
\end{array}\right]=\left[\begin{array}{cc}
K_{a} \otimes A & 0 \\
0 & R
\end{array}\right]
$$

where $K_{a}$ is the (co)variance matrix between random-regression coefficients for direct additive genetic effects, $A$ is the relationship matrix between individuals, $\otimes$ is the Kronecker product between matrices, and $R$ is a diagonal block matrix containing residual variances. The relationship matrix consisted of 137,893 animals in the complete pedigree, with 93,446 animals in the dataset, including 807 sires and 37,285 cows with calves with records.

The covariance functions were estimated by the restricted maximum likelihood method using the Wombat program (Meyer, 2006). Additionally, single-trait analyses (finite model) were performed for $\mathrm{AFC}, \mathrm{SC}$ and $\mathrm{YW}$, considering an environment shared by all animals, which was used for the subsequent prediction of sires' breeding values in each environmental gradient. The model included the fixed effect of contemporary group for the three traits and age of animal (linear and quadratic effects) as covariable for SC and YW.

Only sires with offspring in at least 10 environments for the three traits were used for breeding value prediction, corresponding to 151, 167 and 304 sires for AFC, SC and YW, respectively. The breeding values of these sires were also predicted using the reaction norm model in three environments with high (-2.0), moderate (0) and low (2.0) environmental restriction. The following formula was used to estimate the breeding values for each EG by reaction norm analysis:

$$
E B V_{i \mid E G}=\sum_{m=0}^{k \alpha-1} \propto_{i m} \emptyset_{m} E G
$$

where $\emptyset_{\mathrm{m}}$ and $\propto_{\mathrm{im}}$ are the $m$ th Legendre polynomial as a function of the environmental gradient and the random-regression coefficient for direct genetic effects, respectively. The Spearman correlation coefficient was calculated to compare the ranking of the selected sires based on the breeding values obtained by single-trait and reaction norm analysis. Additionally, 10 sires each with the highest and lowest breeding value for $\mathrm{YW}$ predicted by single-trait analysis were selected. The reaction norm of these 20 sires for YW, SC and AFC was predicted along the EG.

\section{RESULTS AND DISCUSSION}

The overall mean of AFC, SC and YW were $1045 \pm 118$ days (range: 730 to 1460 days), $26.72 \pm 3.46 \mathrm{~cm}$ (range: 18 to $44 \mathrm{~cm}$ ) and $273.49 \pm 43.45 \mathrm{~kg}$ (range: 555.0 to 149.98 $\mathrm{kg}$ ), respectively (Figure 1A, B and C). For YW and SC, an increase in mean values was within groups as the environment became more favorable. 

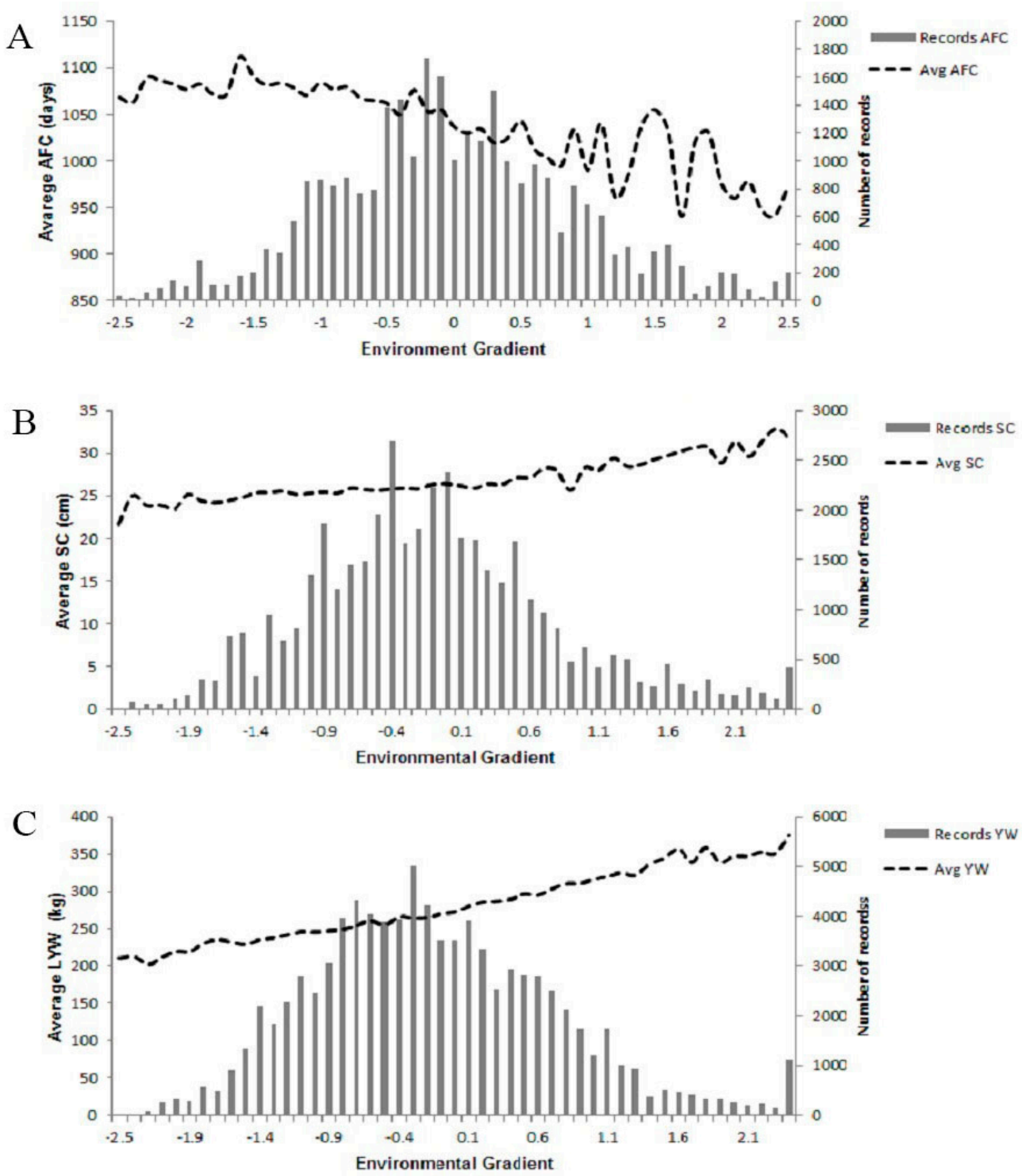

Figure 1. Evolution of age at first calving (AFC; A), scrotal circumference (SC; B) and yearling weight (YW; C) along the environmental gradient and number of observations in each group.

The additive genetic variance estimates $\left(\sigma_{a}^{2}\right)$ for the three traits increased as the environmental gradient became more favorable (Figure 2A, B and C). The increase in variances with improving environmental conditions indicated the presence of a GxE effect. The same behavior for additive genetic variance was observed by Mattar et al. (2011) for weight at 450 days in Canchim cattle.

The additive genetic variance estimates showed the same trend for the three traits studied (Figure 2B). A greater range of variation in additive genetic variances was observed 
for AFC and YW (Figure 2A), highlighting additive genetic differences between animals in more favorable environmental conditions, i.e., the expression of the additive genetic potential was more evident in less restricted environments.
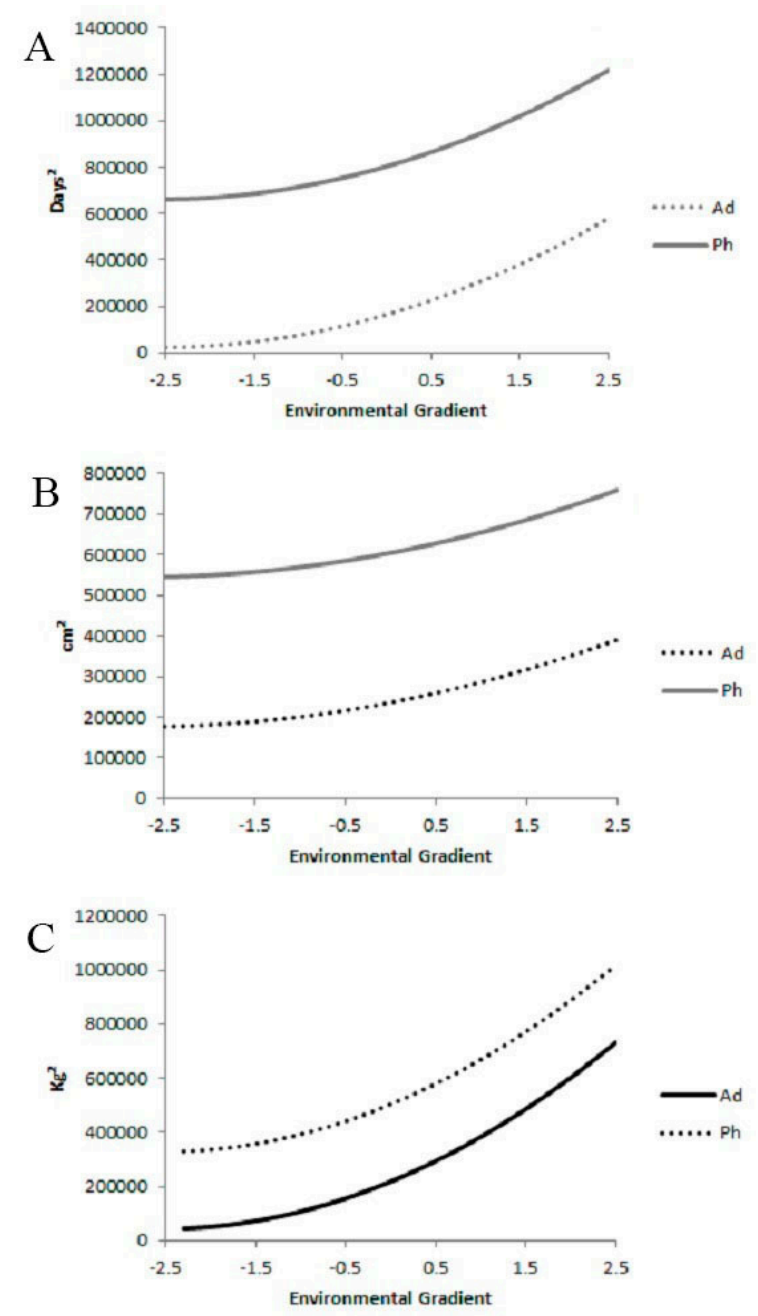

Figure 2. Estimates of additive genetic (Ad) and phenotypic $(\mathrm{Ph})$ variance for age at first calving (A), scrotal circumference $(\mathbf{B})$ and yearling weight $(\mathbf{C})$ along the environmental gradient.

The phenotypic variances obtained for the three traits followed the same trend as the additive genetic variances, with a proportional increase in the estimates with improving environmental conditions, demonstrating a GxE effect on the phenotype of animals (Figure 2C). According to Calus et al. (2002), the presence of $\mathrm{GxE}$ is a consequence of the heterogeneity of variances in different environments, suggesting the presence of GxE effects for the three traits studied. In beef cattle breeding programs the assumption is that the additive genetic variance remains the same along the different environments. 
The same trend for variance components along an EG has been reported in other studies investigating growth and production traits in beef cattle, such as postweaning weight gain at different ages (345 and 450 days) (Cardoso et al., 2005; Cardoso and Campos, 2007; Pégolo et al., 2009; Mattar et al., 2011) and economically important traits in dairy cattle, such as days in milk, somatic cell count, days open, and milk yield (Kolmodin et al., 2002; Oseni et al., 2004; Calus et al., 2005, 2006; Windig et al., 2006; Strandberg et al., 2009). According to Calus et al. (2002), as the environmental conditions become more favorable, the animals find greater opportunities to express their genotype, and there is an increase in the expression of the breeding value of animals.

The heritability estimates were low to moderate magnitude for $\mathrm{AFC}(0.05$ to 0.47$)$, moderate to high magnitude for SC ( 0.32 to 0.51$)$, and low to high magnitude for $\mathrm{YW}(0.13$ to 0.72) (Figure 3). The variation in heritabilities obtained in this study are consistent since they are within the range reported in the literature for Nellore cattle, ranging from 0.01 to 0.37 for AFC (Gressler et al., 2000; Bertazzo et al., 2004), from 0.36 to 0.71 for SC (Garnero et al., 2001; Dias et al., 2003; Yokoo et al., 2007), and from 0.08 to 0.76 for YW (Ribeiro et al., 2001; Mucari and Oliveira, 2003).

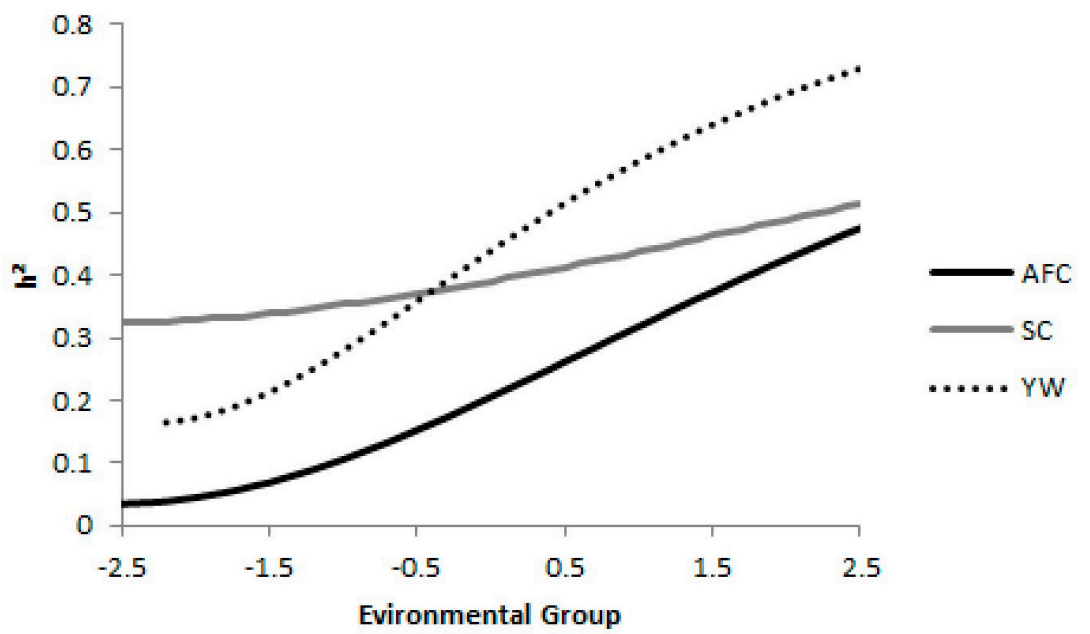

Figure 3. Estimates of heritability (h2) for age at first calving (AFC), scrotal circumference (SC), and yearling weight (YW) along the environmental gradient.

Toral et al. (2004) observed the same variation trend in a study analyzing the effect of GxE on growth traits in Nellore cattle. The authors evaluated the traits in three different microregions and obtained heritabilities ranging from 0.16 to 0.66 for birthweight, 0.36 to 0.59 for weight at 205 days, 0.35 to 0.49 for weight at 365 days, and 0.30 to 0.45 for weight at 550 days. Similarly, Mattar et al. (2011), investigating the presence of GxE for YW in Canchim cattle by reaction norm analysis, obtained increasing heritability estimates with improved environmental conditions, which ranged from 0.08 to 0.68 .

The same trend in heritability estimates has been reported in different studies designed to quantify the influence of $\mathrm{G} \times \mathrm{E}$ on growth and production traits in beef cattle. The heritabilities found in those studies increased as the environment became more favorable (Fikse et al., 2003; Shariati et al., 2007; Corrêa et al., 2009; Pégolo et al., 2009; Strandberg et al., 2009). 
For production traits and milk components (milk, protein, and fat), the heritability estimates increased with improving environmental conditions (Calus and Veerkamp, 2003). Thus, the increase in the expression of the genetic potential of animals is influenced by improvements in the environment to which the animals are subjected. As the environment becomes more favorable, the expression of the animal's genetic potential increases and, consequently, the additive genetic differences between animals. The results of this study indicated that a greater response to selection for $\mathrm{YW}, \mathrm{SC}$ and $\mathrm{AFC}$ can be expected as the environment improves through the improvement of management and nutritional conditions.

The genetic correlations between different EG showed a saddle-shaped response surface, ranging from 0.25 to 1.0 (Figure 4A). Higher genetic correlations were observed when the environments were closer or more similar, and lower estimates were obtained for distant environments. The same trend was found for $\mathrm{SC}$, with genetic correlations ranging from 0.71 to 1.0 (Figure 4B). The genetic correlations for YW ranged from 0.42 to 1.0 between different environments (Figure 4C), with higher correlations between more favorable environments.
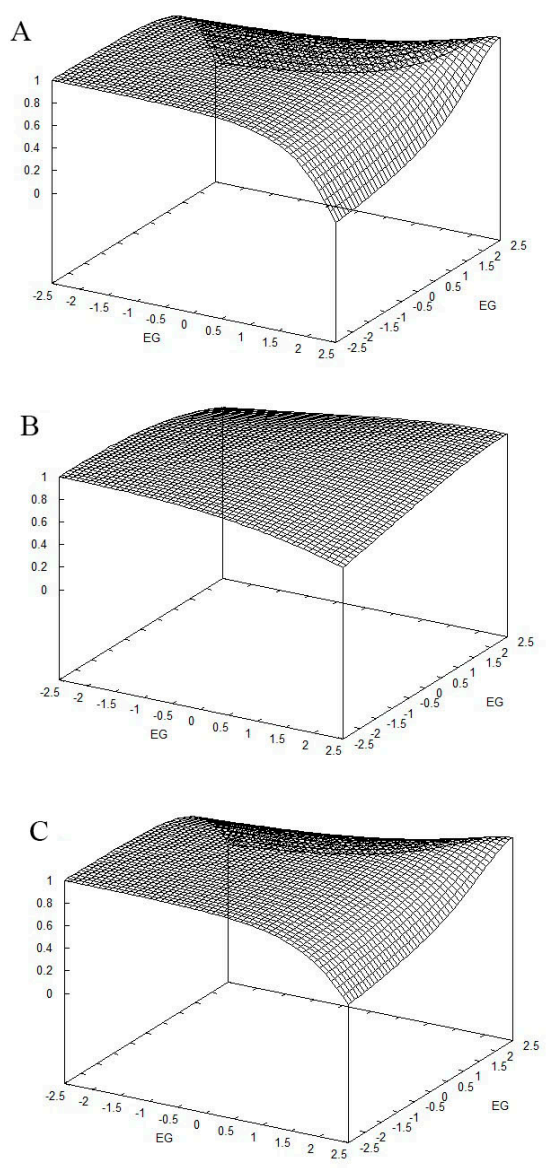

Figure 4. Estimates of genetic correlation for age at first calving (A), scrotal circumference $(\mathbf{B})$ and yearling weight (C) along the environmental gradient (EG). 
In a study evaluating the effect of GxE on YW in Canchim cattle, also using reaction norm analysis, Mattar et al. (2011) observed the same trend for genetic correlation estimates, with estimates ranging from 0.25 to 1.0. Similarly, Pégolo et al. (2009) demonstrated the presence of GxE effects on weight at 450 days in Nellore cattle, with genetic correlations lower than 0.8. Once the influence of the environment on the genetic parameter estimates of the traits studied was determined, the effect of GxE on the selection of animals for AFC, SC and YW in environments with low (2), medium (0) and high (-2) restriction was evaluated. Table 1 shows the rank correlations between sire breeding values obtained with the single-trait and reaction norm models.

Table 1. Spearman correlations between sire breeding values for age at first calving (AFC), scrotal circumference (SC), and yearling weight (YW) obtained by single-trait and reaction norm analysis at different environmental gradients (EGs).

\begin{tabular}{lllll}
\hline & & AFC & SC & YW \\
\hline EG & -2 & 0.98 & 0.99 & 0.93 \\
& 0 & 0.98 & 0.99 & 0.99 \\
& 2 & 0.97 & 0.99 & 0.98 \\
\hline
\end{tabular}

Spearman correlations between breeding values obtained with the reaction norm or single-trait model were high for the three traits (AFC, SC and YW), ranging from 0.97 to 0.99 . This finding indicates little change in the ranking of animals in the three environments, i.e., it is expected that the same sires are selected when breeding values for AFC, SC and YW are predicted with the reaction norm or single-trait model. These results corroborated the findings of Mattar et al. (2011) obtained for Canchim cattle, who found Spearman correlations for YW varying from 0.91 to 0.97 between different environments characterized by low, medium and high restriction.

Figure $5 \mathrm{~A}$ and $\mathrm{B}$ shows the reaction norms across the $\mathrm{EG}$ for $\mathrm{AFC}, \mathrm{SC}$ and $\mathrm{YW}$ of 10 sires with the highest and lowest breeding value for YW predicted by single-trait analysis. A slight change in sire ranking was observed along the EG, especially in extreme environments.

Since YW is an important trait and commonly used in breeding programs, the same sires selected for highest and lowest YW were used for the analysis of reaction norms for AFC and $\mathrm{SC}$ to evaluate the effect of selection for $\mathrm{YW}$ on these traits (Figure 5C, D, E, and F).

Sires with the highest breeding values for YW were more sensitive to environmental changes since the change in the magnitude of the trajectories of their breeding values was greater, showing an upward trend as the environmental conditions improved (Figure 5A). When sires with lower breeding values for YW were selected, the variation in the trajectory of their breeding values occurred at the same proportion as that observed for animals with higher breeding values for $\mathrm{YW}$, but in the opposite (decreasing) direction, indicating a decrease in the breeding values of those sires along the EG with improving environmental conditions (Figure 5B).

A negative variation along the EG was observed for some sires, i.e., their breeding value for AFC was lower than at the beginning when these animals were subjected to more favorable environmental conditions (Figure 5C and D). This finding demonstrates a favorable behavior in relation to this trait, indicating that in more favorable environments, the sires selected will be more precocious for YW and AFC. The same did not occur when sires with lower breeding values for YW had their trajectories traced for AFC. These animals showed an upward trend due to the increase in sire breeding values along the EG. 

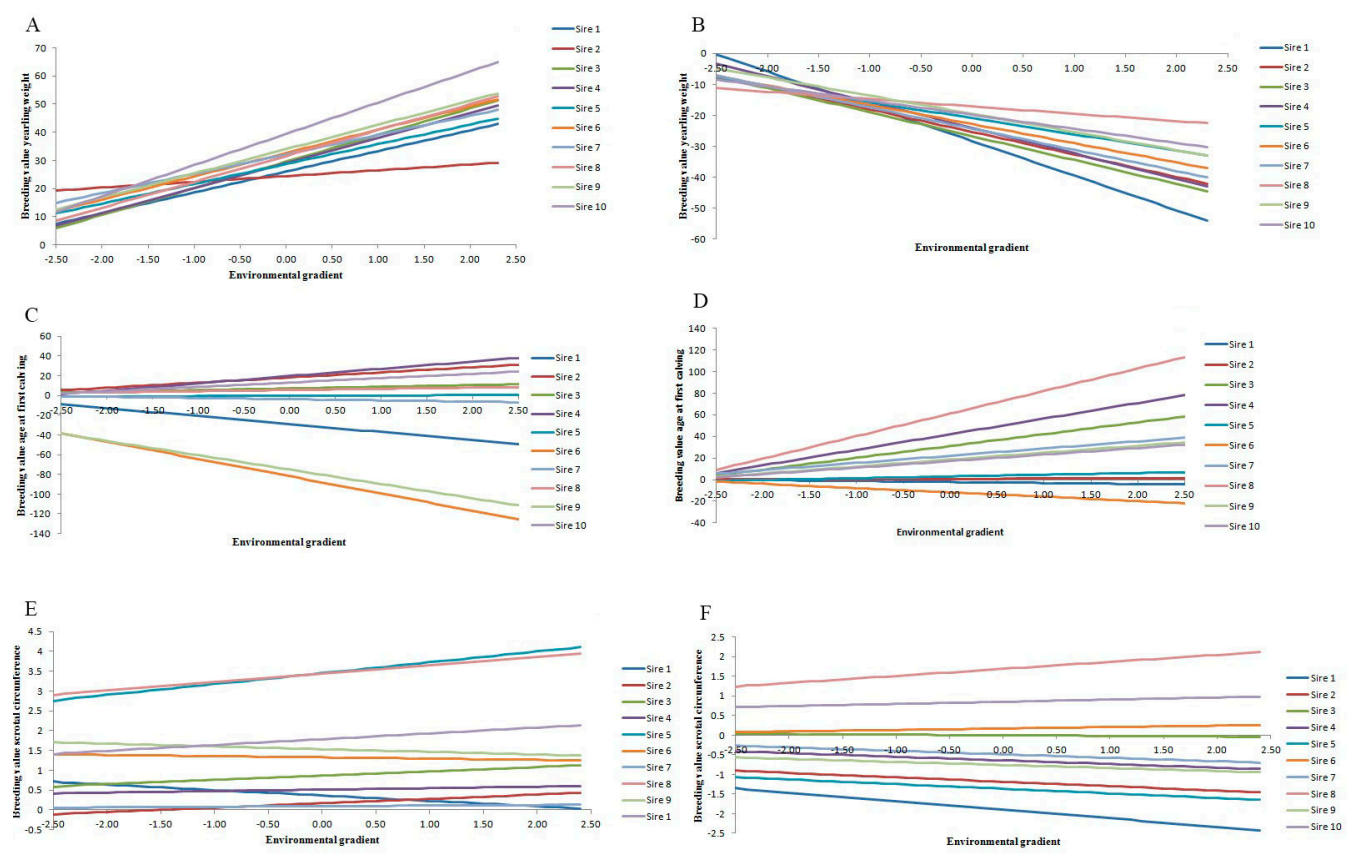

Figure 5. Reaction norms along the environmental gradient for yearling weight (A. B.), age at first calving (C. D.) and scrotal circumference (E. F.) obtained for 10 sires with the highest (left) and lowest (right) breeding value for long-yearling weight.

The reaction norms for $\mathrm{SC}$ did not show a different trend from that obtained for the other two traits (YW and AFC) when compared to sires with higher breeding values for YW. These norms showed upward trajectories, but with a small slope, indicating an increase in the breeding values of these sires along the EG (Figure 5E). Analysis of the 10 sires selected based on the lowest breeding values for YW and their trajectories for SC showed an increase in the breeding value of some of these animals along the EG, a trend similar to that seen in the group of sires selected for higher breeding values for YW (Figure 5F).

A higher incidence of plastic genotypes was observed among animals selected for higher breeding values for YW. These genotypes showed more marked slopes, with extreme sensitivity to environmental changes. Animals with higher environmental sensitivity may show a greater response to more favorable environments, guaranteeing an increase in the population average when these animals are exposed to the most favorable environments. However, plastic genotypes are more affected when exposed to more restricted environments (Falconer, 1990). The same scale effect was observed for AFC and SC, which had more plastic genotypes when compared to animals selected for lower breeding values for YW.

The incidence of more robust genotypes could be demonstrated by the smaller inclination of the slopes in the graphs of animals selected for lower breeding values for YW. According to Stearns (1989), regarding adaptability, animals with robust genotypes have more difficult in adapting to certain environmental conditions and may be unable to survive under some of these conditions. The environmental sensitivity of beef cattle has been the subject in the studies of Cardoso et al. (2005) and Cardoso and Campos (2007) for Angus cattle, Mattar 
et al. (2011) involving Canchim cattle, and Santana et al. (2012) involving Montana cattle. These authors used reaction norms of individuals in different environments to determine the behavior of genotypes.

The magnitude of GxE effects on SC was lower when this trait was analyzed on the basis of the variations in heritability and variance components along the EG, with these variations being smaller when compared to AFC and YW. The genetic correlations indicate a higher magnitude of GxE effects on YW and AFC, with the estimates being lower than 0.8 (Robertson, 1959). The results of reaction norm analysis of sires showed that extreme genotypes, with a high and low breeding value for $\mathrm{YW}$, should respond differently as the environmental conditions improve, demonstrating the presence of GxE. In this respect, animals with a higher breeding value show greater plasticity. However, the rank of sires is not expected to change in the different environments evaluated for the three traits. Therefore, the same animals should be selected regardless of whether or not GxE effects are considered.

\section{CONCLUSIONS}

The effect of GxE was most important for YW and AFC with respect to SC. The response to selection along the EG is expected to be higher in more favorable environments. When animals are selected for higher SC or YW or lower AFC, considering or not the GxE effect, it is expected that the same animals will be selected.

The reaction norms obtained on the basis of sire breeding values along the EG showed that animals with extreme breeding values should respond differently as environmental conditions improve. In this respect, animals with a greater genetic growth potential are more plastic for growth and indicator traits of sexual precocity.

\section{ACKNOWLEDGMENTS}

M.V.A. Lemos, F.L.B. Feitosa and C. Aboujaoude received scholarships from FAPESP (Fundação de Amparo à Pesquisa do Estado de São Paulo). H.L.J. Chiaia and M.P. Berton received scholarships from CAPES (Coordenação de Aperfeiçoamento de Pessoal de Nível Superior) in conjunction with the Postgraduate Program on Genetics and Animal Breeding, Faculdade de Ciências Agrárias e Veterinárias, Universidade Estadual Paulista. G.C. Venturini received scholarships from CNPq (Conselho Nacional de Desenvolvimento Científico e Tecnológico). H.N. Oliveira, L.G. Albuquerque, and F. Baldi held a productivity research fellowship from CNPq (Conselho Nacional de Desenvolvimento Científico e Tecnológico).

\section{REFERENCES}

Alencar MM, Mascioli AS and Freitas AR (2005). Evidências de interação genótipo-ambiente sobre características de crescimento em bovinos de corte. R. Bras. Zootec. 34: 489-495.

Bertazzo RP, Freitas RTF, Gonçalves TM, Pereira IG, et al. (2004). Parâmetros genéticos de longevidade e produtividade de fêmeas da raça Nelore. R. Bras. Zootec. 33: 1118-1127.

Boligon AA, Rorato PRN and Albuquerque LG (2007). Correlações genéticas entre medidas de perímetro escrotal e características produtivas e reprodutivas de fêmeas da raça Nelore. $R$. Bras. Zootec. 36: 565-571.

Calus MP and Veerkamp RF (2003). Estimation of environmental sensitivity of genetic merit for milk production traits using a random regression model. J. Dairy Sci. 86: 3756-3764.

Calus MP, Groen AF and Jong G (2002). Genotype x environment interaction for protein yield in Dutch dairy cattle as quantified by different models. J. Dairy Sci. 85: 3115-3123.

Calus MP, Bijma P and Veerkamp RF (2004). Effects of data structure on the estimation of covariance functions to 
describe genotype by environment interactions in a reaction norm model. Genet. Sel. Evol. 36: 489-507.

Calus MP, Carrick MJ, Veerkamp RF and Goddard ME (2005). Estimation of Genetic Parameters for Milk Fat Depression in Dairy Cattle. J. Dairy Sci. 88: 1166-1177.

Calus MP, Janss LLG and Veerkamp RF (2006). Genotype by environment interaction for somatic cell score across bulk milk somatic cell count and days in milk. J. Dairy Sci. 89: 4846-4857.

Cardoso FF and Campos LT (2007). Modelos hierárquicos Bayesianos para estudo de interação genótipo-ambiente vias normas de reação aplicados ao ganho pós desmama de bovinos Angus. In: Reunião Anual da Sociedade Brasileira de Zootecnia, Jaboticabal.

Cardoso FF, Cardellino RA and Campos LT (2005). Caracterização de interação genótipo-ambiente no ganho pósdesmama de bovinos Angus via normas de reação. In: Reunião Anual da Sociedade Brasileira de Zootecnia, Goiânia.

Corrêa MBB, Dionello NJL and Cardoso FF (2009). Caracterização da interação genótipo-ambiente e comparação entre modelos para ajuste do ganho pós-demama de bovinos Devon via normas de reação. R. Bras. Zootec. 38: 1468-1477.

Dias LT, Faro LE and Albuquerque LG (2003). Estimativa de correlação genética entre perímetro escrotal e idade ao primeiro parto para animais da raça Nelore. Arq. Bras. Med. Vet. Zootec. (Numeros da revista não encontrado)

Falconer DS (1990). Selection in different environments: effects on environmental sensitivity (reaction norm) and on mean performance. Genet. Res. 56: 57-70.

Falconer DS and Mackay TFC (1996). Introduction to quantitative genetics. Longman Group, Harlow.

Fikse WF, Rekaya R and Weigel KA (2003). Assessment of environmental descriptors for studying genotype by environment interaction. Livest. Prod. Sci. 82: 223-231.

Garnero AV, Lôbo RB, Bezerra LAF and Oliveira HN (2001). Comparação entre alguns critérios de seleção para crescimento na raça Nelore. R. Bras. Zootec. 30: 714-718.

Gressler SL, Bergmann JAG, Pereira CS, Penna VM, et al. (2000). Estudo das associações genéticas entre perímetro escrotal e características reprodutivas de fêmeas Nelore. R. Bras. Zootec. 29: 427-437.

Kirkpatrick M, Lofsvold D and Bulmer M (1990). Analysis of the inheritance, Selection and Evolution of Growth Trajectories. Genetic 124: 979-993.

Kolmodin R, Strandberg E, Madsen P, Jensen J, et al. (2002). Genotype by environment interaction in Nordic dairy cattle studied using reaction norms. Acta Agric Scand. A. Anim. Sci. 52: 11-24.

Mattar M, Silva LOC, Alencar MM and Cardoso FF (2011). Genotype x environment interaction for long-yearling weight in Canchim cattle quantified by reaction norm analysis. J. Anim. Sci. 89: 2349-2355.

Meyer K (2006). "WOMBAT" - Digging deep for quantitative genetic analyses by restricted maximum likelihood. In: Proceedings of the 8th World Congress on Genetic Applied to Livestock Production, Belo Horizonte.

Mucari TB and Oliveira JA (2003). Análise genético-quantitativa de pesos aos 8, 12, 18 e 24 meses de idade em um rebanho da raça Guzerá. R. Bras. Zootec. 32: 1604-1613.

Oseni S, Misztal I, Tsuruta S and Rekaya R (2004). Genetic Components of Days Open Under Heat Stress. J. Dairy Sci. 87: 3022-3028.

Pégolo NT, Oliveira HN, Albuquerque LG, Bezerra LAF, et al. (2009). Genotype by environment interaction for 450-day weight of Nelore cattle analyzed by reaction norm models. Genet. Mol. Biol. 32: 281-287.

Pereira E, Eler JP and Ferraz JBS (2002). Análise genética de características reprodutivas na raça Nelore. Pesq. Agropec. Bras. 37: 703-708.

Ribeiro MN, Pimenta Filho EC, Martins GA, Sarmento JLR, et al. (2001). Herdabilidade para efeitos diretos e maternos de características de crescimento de bovinos Nelore no estado da Paraíba. R. Bras. Zootec. 30: 1224-1227.

Robertson A (1959). The sampling variance of the genetic correlation coefficient. Biometrics 15: 469-485.

Santana MLJ, Eler JP, Cardoso FF, Albuquerque LG, et al. (2012). Phenotypic plasticity of composite beef cattle performance using reaction norms model with unknown covariate. Animal 7: 202-210.

Shariati MM, Su G, Madsen P and Sorensen D (2007). Analysis of milk production traits in early lactation using a reaction norm model with unknown covariates. J. Dairy Sci. 90: 5759-5766.

Stearns SC (1989). The evolutionary significance of phenotypic plasticity. Biol. Sci. 39: 436-445.

Strandberg E, Brotherstone S, Wall E and Coffey MP (2009). Genotype by environment interaction for first-lactation female fertility traits in UK dairy cattle. J. Dairy Sci. 92: 3437-3446.

Toral FLB, Silva LOC, Martins EL, Gondo A, et al. (2004). Interação genótipo-ambiente em características de crescimento de bovinos da raça Nelore no Mato Grosso do Sul. R. Bras. Zootec. 33: 1445-1455.

Windig JJ, Calus M, Beerda B and Veerkamp RF (2006). Genetic correlations between milk production and health and fertility depending on herd environment. J. Dairy Sci. 89: 1765-1775.

Yokoo MJI, Albuquerque LG, Lôbo RB and Sainz RD (2007). Estimativas de parâmetros genéticos para altura do posterior, peso e circunferência escrotal em bovinos da raça Nelore. R. Bras. Zootec. 36: 176. 